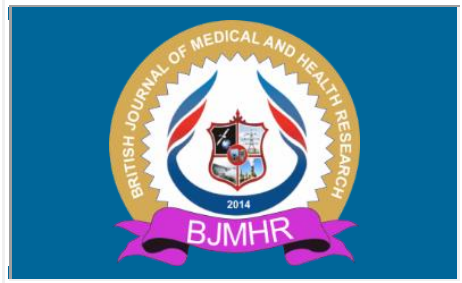

\title{
BJMHR
}

British Journal of Medical and Health Research

Journal home page: www.bjmhr.com

\section{Inveterate Elbow Dislocation: Surgical Reduction with Triceps Lengthening (A Case Report)}

\section{Yassine Rachdi*, Adnane Lachkar, Abdeljaouad Najib, Hicham Yacoubi.}

Department of traumatology and orthopedics, Mohammed VI university hospital center, Oujda, Morocco

\section{ABSTRACT}

Inveterate elbow dislocations remain common in developing countries. We report the case of a 17-year-old child who consulted us after six months of trauma to the left elbow. Clinical examination revealed a deformed elbow, locked in extension with a mobility sector of $5^{\circ}$. The Mayo Clinic Elbow performance score was sixty-six; the downstream vasculo-nervous examination was normal. The face and profile X-ray of the elbow showed a pure posterolateral elbow dislocation. We used the posterior medial para-tricipital and lateral approach, a first stage of arthrolysis was performed. A complete reduction was achieved by progressive and non-traumatic gentle maneuvers. Intraoperative elbow flexion was less than $80^{\circ}$, indicating a retraction of the triceps muscle, so a Z-lengthening plasty was necessary. This reduction was then fixed with two olecranon-humeral K-wires. At the third week, the plaster cast and K-wires were removed. The patient was subsequently referred to a physical therapist. After a ten-month follow-up, an undistorted and functional elbow with a gain of twenty-one points according to the Mayo Clinic score was obtained. Surgical reduction of a neglected elbow dislocation with triceps lengthening plasty, followed by a codified physical therapy program, results in a remarkable restoration of elbow function and stability.

Keywords: elbow, dislocation, inveterate, reduction, triceps. 


\section{INTRODUCTION}

Inveterate elbow dislocations are defined as dislocations not treated within three weeks of trauma ${ }^{1}$, they are still frequent in developing countries. Stiffness of the elbow in a nonfunctional area is the main cause of the consultation. We report the case of a neglected dislocation of the elbow reduced to open focus. The objective of our work was to present our experience in the surgical reduction with tricepsplasty of an inveterate dislocation by posterior approach.

\section{CASE REPORT:}

Child H.H, 17 years old, presented with a trauma of the left elbow following a fall from a horse. The patient was simply immobilized by a Jbira elbow in extension for 15 days. Six months later, the patient consulted for elbow stiffness. Clinical examination revealed a deformed elbow with loss of anatomical relief, locked in extension, with a mobility sector of $5^{\circ}$ in activo-passive and normal prono-supination (Figure 1). The Mayo Clinic Elbow performance score was sixty-six, the downstream vasculo-nervous examination was unremarkable. the standard X-ray of the elbow, front and side, showed a posterolateral dislocation of the left elbow, associated with heterotopic ossifications classified as type II according to the Hastings classification. We also note the absence of associated fractures (Figure 2).

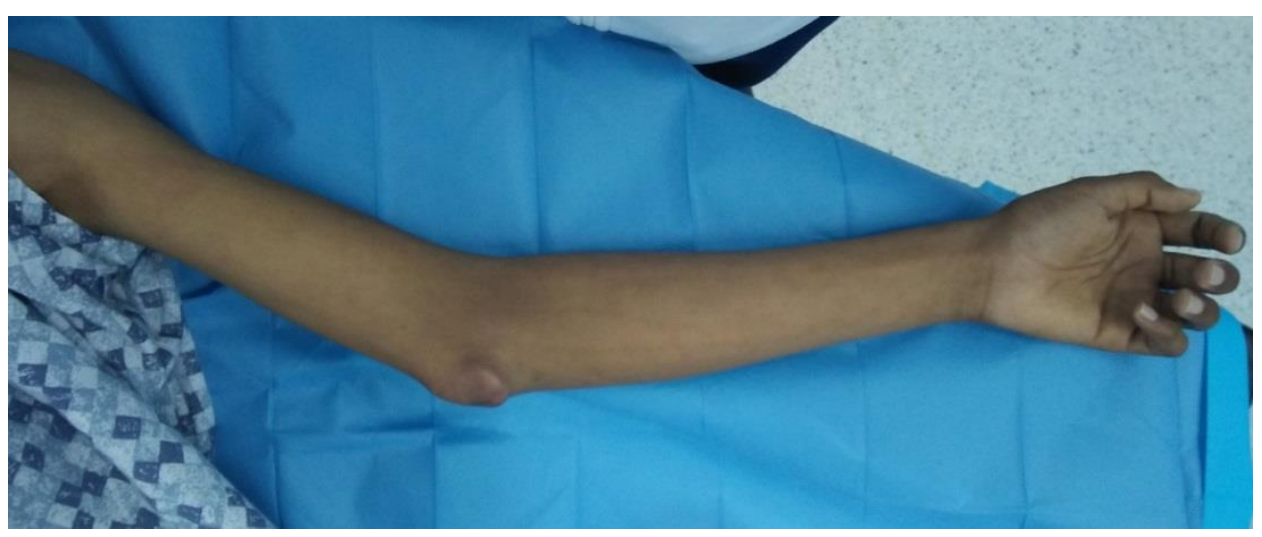

Figure 1: Clinical aspect of the elbow. 


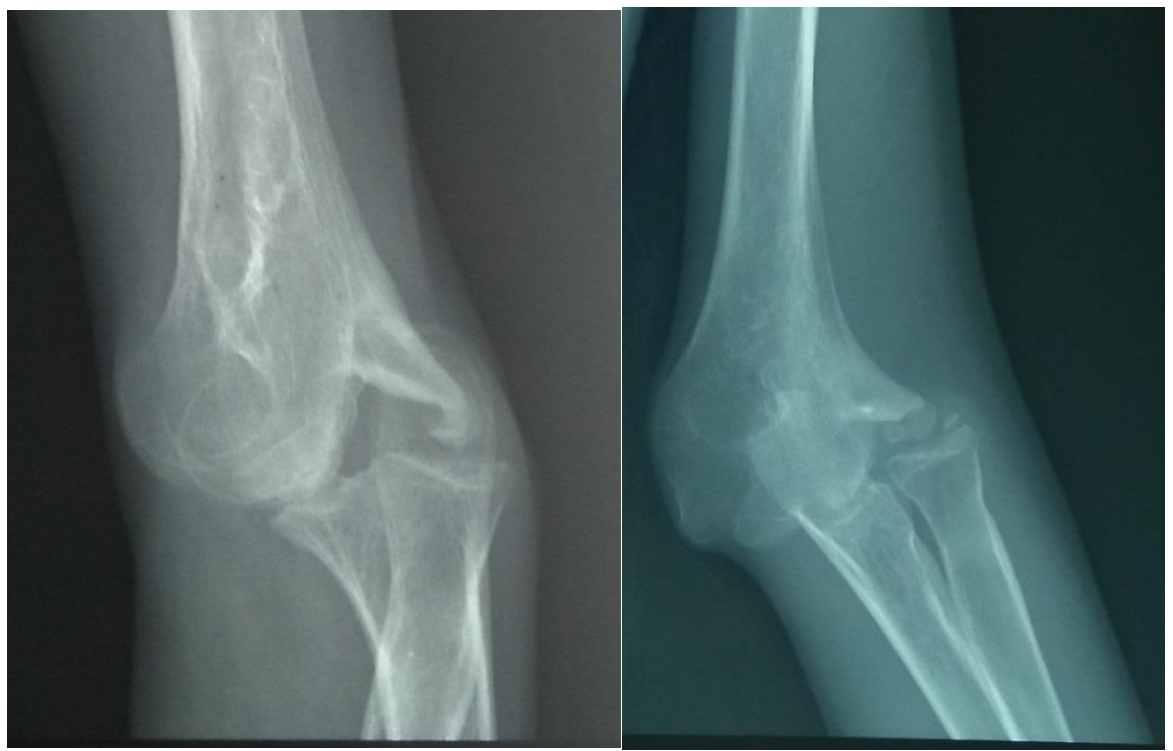

Figure 2: Elbow x-ray: posterolateral elbow dislocation with heterotopic calcifications

Under locoregional anaesthesia by axillary block, on an ordinary table, the patient is installed in lateral decubitus; the arm resting on a support, the forearm is at $90^{\circ}$, without pneumatic tourniquet

We used the posterior medial para-tricipital and lateral approach. Exploration confirmed the posterolateral dislocation with the presence of heterotopic ossifications and an olecranon fossa filled with fibrosis, with remodeling of the articular surfaces. A first stage of arthrolysis was performed, consisting of the resection of the periarticular ossifications, bone blocks and fibrous tissue, noting that the proximal insertions of the collateral ligaments were not resected. A complete reduction was achieved by gentle, progressive, non-traumatic maneuvers. Intraoperative elbow flexion was less than $80^{\circ}$, indicating a retraction of the triceps muscle, so a Z-plasty was necessary (Figure 3). This reduction was then fixed with two olecranon-humeral K-wires (Figure 4). After closure with a suction drain, a brachio-antebrachio-palmar splint was made. 


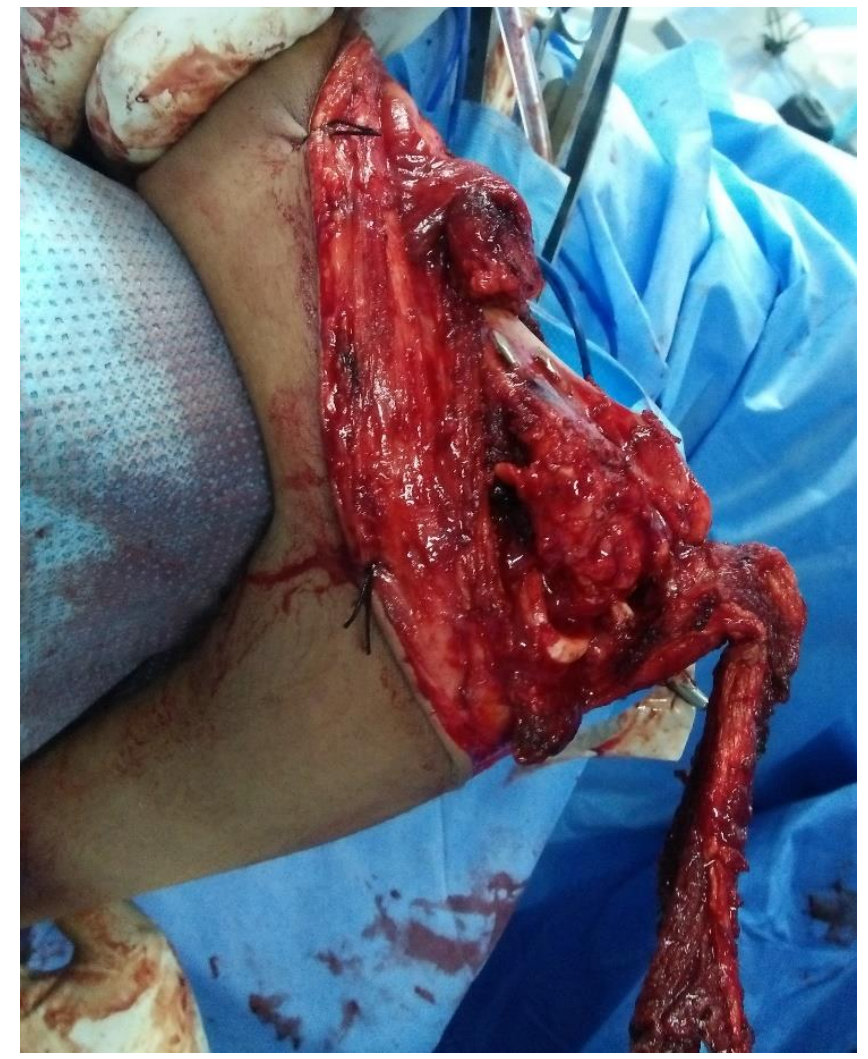

Figure 3: intraoperative image showing: reduction, $Z$ triceps incision, and olecranonhumeral K-wires.

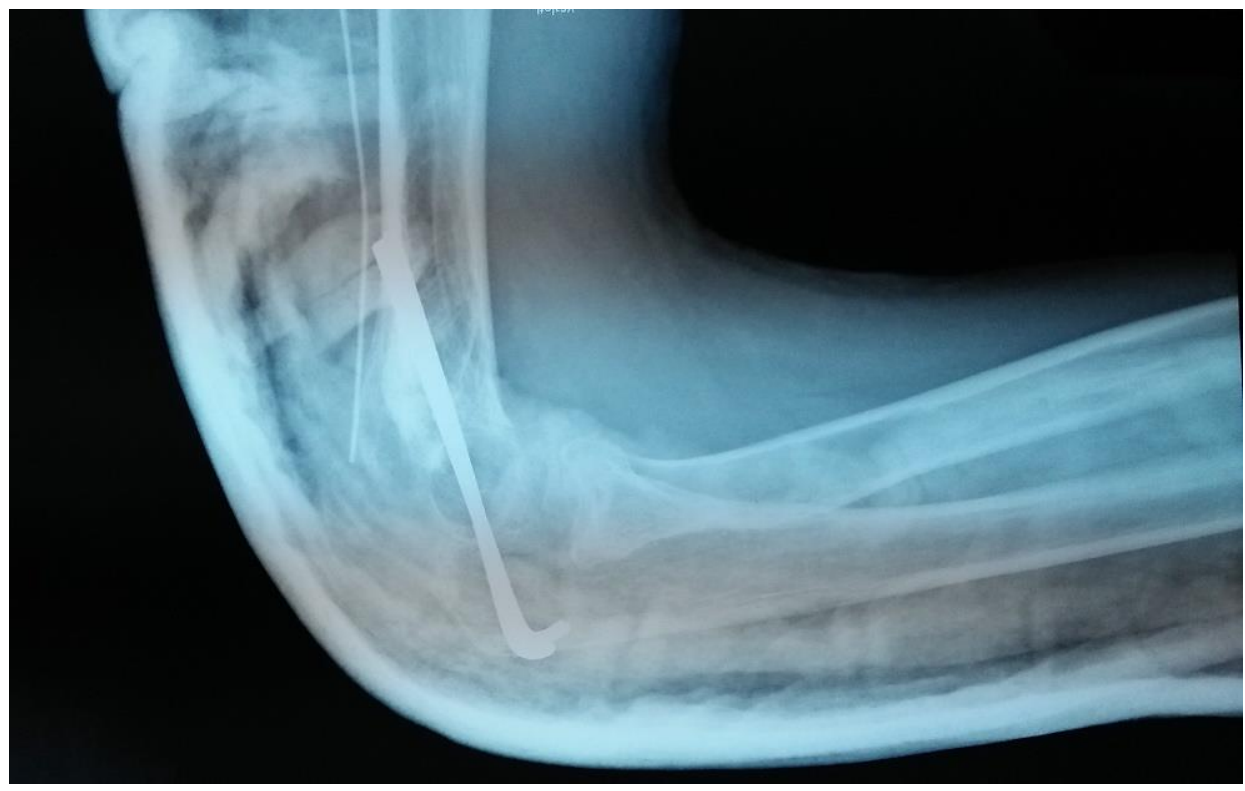

Figure 4: Postoperative control X-ray

The postoperative follow-up was simple. At the third week, the plaster splint and the K-wires were removed. The patient was then referred to a physiotherapist. After a ten-month followup, the elbow was stable and the hand-to-mouth and hand-to-head tests were possible. Flexion was $115^{\circ}$ and extension was $-30^{\circ}$. The prono-supination was normal. The Mayo Clinic Elbow performance score was increased by twenty-one points. 


\section{DISCUSSION:}

After 3 weeks of trauma, soft tissue retractions and localized osteoporosis make closed reduction unsafe, with a risk of fracture ${ }^{2}$. Fowles et al, in their study of 15 children with untreated posterior elbow dislocation, found that those seen within 2 months of trauma could regain functional elbow mobility without surgery, and they recommended a trial of bloodless reduction in such cases ${ }^{3}$.

Mahaisavariya and Laupattarakasem in their study recommended an open reduction without triceps lengthening to achieve better elbow flexion after negligent dislocation within 1 to 3 months ${ }^{4}$. The same authors in another series performed triceps lengthening with collateral ligament repair in 22 of 24 cases of neglected elbow dislocation for a period of 1 to 6 months Some authors ${ }^{5,6}$ and in particular Martini ${ }^{7}$ have emphasized the adaptation of the dislocated elbow with time. Martini ${ }^{7}$ does not systematically operate on neglected elbow dislocations. Bloody reduction remains the frequent but not systematic indication. The author definitively refrains from operating when stiffness is at the limit of functional adaptation and may improve after a few weeks of rehabilitation. According to Dishino, elbow stiffening in children is rapid, and a bloody reduction must be performed early to avoid a more mutilating surgery later on ${ }^{8}$.

Morrey has grouped the various possible issues that need to be addressed ${ }^{9}$. These include: triceps retraction, collateral and capsular ligaments, ulnar nerve involvement, intra-articular fibrosis, and associated coronoid or radial head fracture in $30 \%$ to $40 \%$.

Most authors recommend the posterior approach over the lateral approach combined with the medial approach ${ }^{10}$. In cases of significant retraction of the triceps, two main techniques have been proposed: Speed's V-Y tricepsplasty ${ }^{11}$, which is the most commonly used ${ }^{12}$, and Vangorder's technique ${ }^{13}$. The latter uses an Achilles tendon or fascia lata allograft after transection of the triceps. If primary elbow flexion is greater than 110 degrees, no triceps lengthening should be considered ${ }^{14}$.

Regarding the attitude towards the ulnar nerve, Silva regularly transposed the ulnar nerve in his series of inveterate dislocations ${ }^{15}$. Bruce and his colleagues recommend that the ulnar nerve be inspected and decompressed systematically in all cases in which bloody reduction is necessary ${ }^{16}$.

Instability after open reduction, resulting from release of the ligaments, capsule and triceps has often been noted by several authors ${ }^{17}$, therefore they have resorted to trans-articular pinning and casting at $90^{\circ}$ flexion for 2 to 4 weeks postoperatively to maintain a stable elbow

\section{CONCLUSION:}

Surgical reduction of a neglected elbow dislocation with triceps lengthening plasty, followed 
by a codified program of physical therapy, results in remarkable restoration of elbow function and stability. The early and correct management of acute elbow dislocations and easy access to care are the only means of preventing this type of injury.

\section{REFERENCES:}

1. Freeman III BL. Old unreduced dislocations. In: Crenshaw AH, editor. Campbell's operative orthopaedics, 9th ed. St. Louis: Mosby; 1998, p. 2673-4.

2. Rockwood CA. Treatment of old unreduced posterior dislocation of elbow. In: Rockwood CA, editor. 4th ed., Rockwood and Green's fracture in adults, vol. I, 4th ed. Philadelphia, PA: Lippincott-Raven; 1996. p. 975-6.

3. Fowles JV, Kassab MT, Douik M. Untreated posterior dislocation of the elbow in children. J Bone Joint Surg 1984;66-A:921-6.

4. Mahaisavariya B, Laupattarakasen L, Supachutikul A, Taesiri H, Sujaritbudhungkoon S. Late reduction of dislocated elbow need triceps be lengthened? J Bone Joint Surg $1993 ; 75-B: 426-8$.

5. Bourrel P, Huet R, Gourillon H, Fillandeau G, Malchair G, Chatelan JP. Luxations traumatiques anciennes outre-MER. À propos de 25 cas: épaule, coude, métacarpophalangiennes, hanches. Med Trop 1968;28(4):1-21.

6. Krisham M. Management of the old elbow dislocations. Int Surg 1971; 56:159-65.

7. Martini M, Benselma R, Daoud A. Les luxations négligées du coude 25 repositions sanglantes. Rev Chir Orthop 1984;70:305-12.

8. Di Shino M, BredaY, MerrienY. La réduction à foyer ouvert du coude. À propos de 29 luxations négligées. Med Trop 1989;49(4):421-6.

9. Morrey BF, Adams RA. Semi contrained arthroplasty for the treatment of rhumatoid arthritis of the elbow. J Bone Joint Surg 1992;74-A:479-90.

10. Billet DM. Unreduced posterior dislocation of the elbow. J Trauma 1979; 19:186 — 8 .

11. Speed JS. An operation for unreduced posterior dislocation of the elbow. South Med J $1925 ; 18: 193-8$.

12. Essi FA, Najeb Y, Latifi M. La voie d'abord postérieure transtricipitale dans les luxations invétérées du coude. Chir Main 2010; 29:321-5.

13. Vangorder GW. Surgical approach in old posterior dislocation of the elbow. J Bone Joint Surg 1932; 14:127-43.

14. Morrey BF. Chronic unreduced elbow dislocations. In: Morrey BF, editor. The elbow and its disorders. Philadelphia: Saunders; 2000. p. 431-6.

15. Silva JF. Old dislocations of the elbow. Ann R Coll Surg Engl 1958; 22(6):363-81. 
16. Bruce C, Laing P, Dorgan J, et al. unreduced dislocation of the elbow: case report and review of the literature. J Trauma 1993;35(6):962-5.

17. Naidoo KS. Unreduced posterior dislocations of the elbow. J Bone Joint Surg $\mathrm{Br}$ 1982;64:603-6.

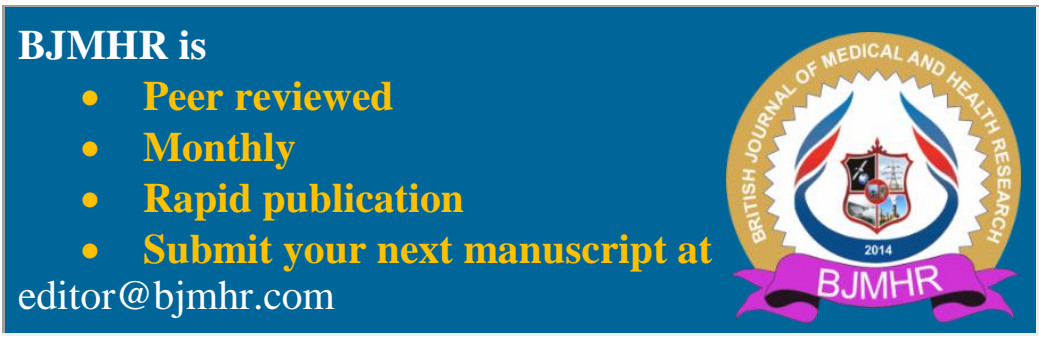

